Laboratorio de Arte,4-1991 http://dx.doi.org/10.12795/LA.1991.i04.03

\title{
EL HOSPITAL DE SAN LÁZARO EN SEVILLA. DE FUNDACIÓN MEDIEVAL A EDIFICIO RENACENTISTA
}

\author{
por RAFAel Cómez
}

\begin{abstract}
Este artículo intenta una aproximación a la historia del edificio conocido como Hospital de San Lázaro en Sevilla, una institución de fundación y patrocinio real, que ha mantenido su uso hospitalario desde la Edad Media hasta nuestros días.

This article summarizes the architectural history of the Hospital of San Lázaro in Seville, a royal foundation which has continued to be used as a hospital from the Middle Ages to the present day.
\end{abstract}

El Hospital de San Lázaro en Sevilla constituye un primer eslabón, el más antiguo, en la larga cadena de la historia de los hospitales sevillanos. Muy poco conocido en sus orígenes, su funcionamiento y su desarrollo histórico y artístico, a pesar de haber sido una de las instituciones hospitalarias hispalenses que haya mantenido ininterrumpidamente su función desde su fundación a mediados del siglo XIII, tras la conquista de la ciudad, hasta nuestros días, el propósito de las páginas que siguen es establecer, ciertamente, una aproximación a la historia del edificio desde sus orígenes medievales hasta la construcción moderna, de tal modo que este estudio que hemos pergeñado sea punto de partida de otras investigaciones que contribuyan al conocimiento de un edificio que, declarado monumento histórico-artístico en 1964, permanece como testigo de la historia de la ciudad en el sufrimiento y el dolor de sus habitantes. 
No resulta fácil indagar acerca de los comienzos de un edificio que vemos hoy día notablemente alterado respecto a su estado original. Tradicionalmente, su existencia se ha relacionado con una torre medieval llamada de los Gausines ' $y$, del mismo modo, a partir de una cita de López Martínez aquélla se ha identificado con "la torre de la capilla del Hospital de San Lázaro" ", existiendo la creencia, en la actualidad, que la denominada torre de los Gausines sea el campanario octogonal que se destaca sobre el ábside de la iglesia.

El equívoco es evidente y una nueva lectura de los textos así como de los muros del edificio nos ha llevado a desentrañar las causas del problema cuya solución definitiva será aportada el día en que un arquitecto restaurador, asistido por un arqueólogo, realicen la labor que merece el más antiguo hospital de la ciudad.

Si acudimos a las páginas de Alonso de Morgado, podemos conocer claramente cuál era el estado de la torre en la segunda mitad del siglo XVI y cuál es el origen de aquella denominación:

"La Casa está pequeño trecho de la ciudad en la Estrada Real, que va para toda Castilla saliendo por la Puerta de Carmona pegada con ella una Torre, que hasta oy permanece de tiempo de Moros. La qual edificaron los dos hermanos muy famosos, entre ellos, llamados los Gausines" 3 .

Estas breves líneas, como se desprende de su lectura, son elocuentes en dos sentidos: por una parte, nos informa acerca de quiénes fueron sus artífices, dos hermanos alarifes llamados Gausines que son los que le han dado el nombre que se ha mantenido hasta nuestros días. Por otra, después de darnos exactamente la ubicación del Hospital, afirma que adherida al edificio hay una torre que se encuentra igual que antes de la conquista cristiana de la ciudad.

Abundando en los cronistas hispalenses, Ortiz de Zúñiga, al hablarnos de las puertas de la ciudad, y referir la de Macarena, menciona "una torre algo distante, a que está junto el hospital de San Lázaro" 4 .

Resulta claro que dicha torre existía con anterioridad al campanario y que, obviamente, ambas torres poseen una entidad diferente. Ahora bien, ¿dónde se halla, pues, actualmente, la torre de los Gausines, punto de partida del viejo Hospital de San Lázaro?

1. J. GESTOSO: Sevilla monumental y artística, III. Sevilla, 1892, p. 522.

2. C. LÓPEZ MARTÍNEZ: Mudéjares y moriscos sevillanos. Sevilla, 1935, p. 34.

3. A. DE MORGADO: Historia de Sevilla. Sevilla, 1587, f. $120 \mathrm{v}$.

4. D. ORTIZ DE ZÚÑIGA: Anales eclesiásticos y seculares de la muy noble y muy leal ciudad de Sevilla. Madrid, 1795, año 1248, I, pp. 41 y 44 : "la torre a que está arrimado el hospital de S. Lázaro". 
A nuestro leal saber y entender, y salvo mejor criterio, la llamada torre de los Gausines no puede ser otra que el bloque rectangular, sensiblemente reformado a través de los tiempos, en el que se abre la portada manierista de ingreso al edificio así como un balcón sobre el que luce un azulejo del siglo XVIII con el escudo real.

Varias razones abonan nuestra hipótesis: en primer lugar su aspecto exterior, cuya cornisa aparece coronada por un doble listel característico de la sobria decoración de la arquitectura militar almohade, y la propia portada que no se encuentra a eje, en el centro de la fachada, como sería lógico, lo cual indica que se mantuvo el primitivo ingreso a la torre con las modificaciones, ampliaciones y reformas pertinentes. Segundo, el grosor de los muros, propio de arquitectura militar, que se advierte accediendo a la segunda planta hoy convertida en residencia de la comunidad de hermanas de la Caridad, que atiende a los enfermos del Hospital; el abovedamiento de la escalera de subida a la segunda planta y la bóveda que cubre el vestíbulo de acceso al edificio. En tercer lugar, finalmente, ha subsistido adherida a otras construcciones como ocurre con otras torres medievales más o menos enmascaradas por cortijos y haciendas en las proximidades de Sevilla, es decir, como corrobora el testimonio de Morgado cuando dice que la Casa de San Lázaro está a poco trecho de la ciudad "pegada con ella una Torre".

Hemos dicho con anterioridad que los orígenes del Hospital de San Lázaro se hayan ligados a la llamada torre de los Gausines, pero, en realidad, allí no existía ningún edificio semejante a los que en las modernas tipologías arquitectónicas denominamos hospitales, ¿cuál era, pues, la situación del Hospital en los años de su creación y en los albores de su funcionamiento? A pesar de las profundas y desaprensivas reformas así como las poco acertadas rehabilitaciones efectuadas en su organización general a través de los tiempos, podemos intentar su reconstrucción imaginaria partiendo de los escasos muros antiguos que aún se tienen en pie.

El lugar elegido para su fundación, a unos dos kilómetros de la ciudad de Sevilla, en un ameno paisaje de huertas, las llamadas Huerta Grande y Huerta Chica de San Lázaro, que se mantuvieron prácticamente hasta nuestros días, y en las proximidades del Guadalquivir, resultaba un lugar idóneo por estar apartado de la ciudad y, al mismo tiempo, bien comunicado con ella a través de una calzada, antigua vía romana, de la cual se conservaban ciertos vestigios así como algunos restos de construcciones romanas en el jardín en el siglo pasado ${ }^{5}$.

5. F. COLLANTES DE TERÁN: Memorias históricas de los establecimientos de caridad de Sevilla y descrip- 
Así pues, el primitivo Hospital debió consistir en un conjunto de construcciones fungibles de materiales perecederos que obviamente no han subsistido y que se hallaban en medio de las huertas bajo la protección de una torre fortificada, como tantas otras zonas de huertas del alfoz de Sevilla.

La existencia de la torre viene corroborada por el testimonio mencionado respectivamente por Morgado ${ }^{6}$ y Ortiz de Zúñiga ${ }^{7}$, que hemos citado con anterioridad. Por otra parte, el hecho de que el conjunto del Hospital estuviese integrado por diversas construcciones que ocupaban cada uno de los enfermos queda de manifiesto cuando leemos el título XLI de las Ordenanzas del Hospital de San Lázaro redactadas en 1393, bajo el reinado de Enrique III:

"De como no se deue tirar la casa al enfermo desque le fuere dada et de lo que en ella es obligado a reparar" 8 .

Es decir, que el Hospital estaba formado por un indeterminado número de casas, correspondientes a cada uno de los enfermos, que le eran entregadas a su llegada al lazareto, las cuales debían arreglar y construir a su costa. Este punto queda perfectamente claro en la explanación de dicho título en que se dice:

“...E el dicho enfermo que en la dicha casa morare que sea tenido de la trastejar e enbarrar e alimpiar los tejados a su costa e todas las otras cosas que en ellas fueren menester de adobar e reparar asi de viejo como de nuevo" $"$.

Por lo tanto, parece ser que el tipo de vivienda consistía en una humilde morada de sencillos muros de adobe con tejado a dos aguas, que había de repararse a expensas de los propios inquilinos. Sin embargo, este tipo era el más modesto y aquéllas no eran las únicas en el conjunto pues en esta pequeña villa del dolor también se hacía patente la distinta extracción social, las diferentes clases sociales y los desiguales niveles y status económicos. En ese mismo título de las Ordenanzas, comprobamos que debió existir otro tipo de construcción, si

ción artística de los mismos. Sevilla, 1844, pp. 12 y 23. Con posterioridad sólo conocemos el trabajo de J. I. CARMONA GARCÍA: El sistema de la hospitalidad pública en la Sevilla del Antiguo Régimen. Sevilla, 1979, y la reciente tesis inédita de F. GARCIA DE LA CONCHA: Corporaciones hospitalarias de la Sevilla de los siglos XIII al XVIII, dirigida por el Profesor Calderón Quijano. Sevilla, 1989, aunque ambas no se ocupan del estudio histórico de la arquitectura que nos interesa.

6. A. DE MORGADO, op. cit.. f. 120 v.

7. D. ORTIZ DE ZÚÑIGA, op. cit.. I, p. 41.

8. Ordenanzas del Hospital de San Lázaro (1393, traslado de 1494), f. 13 r. (Leg. 4, 1,1, Archivo Diputación Provincial de Sevilla).

9. Ibidem, f. 13 v. 
no lujoso, al menos de mejores materiales y más hermoso aspecto, al que se le denomina "palacios", donde vivían ciertos enfermos, más poderosos económicamente, quienes llevaban a sus mujeres, así como otras viviendas en las que moraban mujeres que no tenían marido:

“...E eso mesmo mando que sea fecho en los lugares que fueren asignados en los palacios en que moran los enfermos que trahyan mugeres e las mugeres que no an maridos" ${ }^{10}$.

Más adelante completamos la noción que podamos tomar del Hospital medieval cuando se establecen las condiciones en que se debe arrendar un mesón que estaba "junto e cerca de la dicha casa de Sant Lazaro", pues se mencionan los establos que había en aquel albergue "para las bestias para los romeros que vienen a velar a la capilla de la dicha casa" "1.

De todo lo anteriormente expuesto se deduce que al conjunto hospitalario se le llamaba la "casa de Sant Lazaro", destacando sobre las pequeñas construcciones otras de mayor porte a las que denominaban palacios, así como la torre de los Gausines, probablemente residencia del mayoral, administrador del Hospital, y que en caso de peligro, podía convertirse en lugar de refugio y defensa. En segundo lugar, al mencionar el mesón con sus establos para los romeros que acudían a la capilla del Hospital se nos revela un aspecto insólito de una romería al santo patrón no sólo de los leprosos sino también de los mendigos y enterradores. Por último, aquella capilla, edificada tal vez, también, en modestos materiales, sería el antecedente de la iglesia actual, cuyas características inclinan a datarla un siglo más tarde a la fecha de redacción de éstas Ordenanzas.

En este sentido, en San Lázaro ocurrió del mismo modo que en tantos otros hospitales medievales en los que la "institución" precedió al "edificio", habilitándose casas hasta que se construía el edificio "ex-profeso". Claro es que esa peculiaridad propia de los hospitales intramuros adoptaba unas connotaciones diferentes al tratarse de un hospital específico, que había de situarse extramuros a causa de ser la lepra una de las enfermedades temidas cuyos dolientes quedaban proscritos, teniendo que avisar de su presencia por los caminos mediante el sonido de unas tablillas que llevaban en la mano. Además, en la Edad Media existía la creencia de que la humedad favorecía su curación, por los cual los lazaretos se ubicaban en las márgenes de los ríos o en los montes, como sucedió en Asturias ${ }^{12}$.

10. Ibidem.

11. Ibídem, Título XLIII, f. 14 r.

12. V. LAMPÉREZ: Arquitectura civil española de los siglos I al XVIII. II. Madrid, 1927, pp. 254-255. 
No se conocen datos acerca de la construcción de la iglesia y la fecha de su edificación habremos de deducirla necesariamente del análisis de sus formas arquitectónicas.

En primer lugar, hay que mencionar que el templo se halla situado en posición oblicua respecto a la línea horizontal de la fachada del edificio que, obviamente, se levantó en la segunda mitad del siglo XVI. Por lo tanto, independientemente del análisis de sus formas arquitectónicas, la situación de la iglesia, que se encuentra orientada según las prescripciones litúrgicas, revela que fue construida con anterioridad al siglo XVI, es decir, en la etapa medieval de la institución cuando el Hospital no tenía aún la conformación moderna que le caracteriza como tal, aunque no podamos determinar con certeza cual fuera su concreta distribución y planta.

El rectángulo de muros dibuja una planta regular de $24 \times 16 \mathrm{~m}$., con distribución basilical de tres naves, más ancha la central $(5,50 \mathrm{~m}$.) que las laterales $(4$ $\mathrm{m}$.), divididas por pilares cruciformes, destacando un profundo ábside poligonal sostenido exteriormente por cuatro robustos contrafuertes. Adyacente al ábside se encuentra el espacio rectangular de la sacristía en cuyo ángulo N.E. arranca la escalera helicoidal que asciende al campanario. En el lado opuesto del ábside se halla la vivienda del capellán.

El alzado responde a las características propias de las iglesias gótico-mudéjares sevillanas, es decir, una techumbre de madera en forma de artesa, en este caso moderna, sustituyendo a la original, que constituye la armadura de cubierta de la nave principal, más elevada que las laterales, y apoyándose en pilares cruciformes con arcos apuntados que las separan de aquéllas que quedan cubiertas de colgadizo.

El ábside queda cubierto por bóveda gótica de terceletes cuyas nervaduras reposan sobre ménsulas de temas decorativos fitomorfos, e iluminado por un par de ventanas bíforas de huecos alancetados. Tanto el presbiterio como la escalinata que sube hasta él presenta un zócalo de azulejos de arista del siglo XVI. Parece ser que en 1864 se descubrió una pintura mural en el lado próximo a la escalera del púlpito, siendo blanqueada posteriormente ${ }^{13}$. Como quiera que representara la Resurrección de Lázaro y dicho tema iconográfico aparece pintado por Villegas Marmolejo en el retablo de 1553, es probable que la pintura mural fuera realizada con anterioridad a esa fecha, cuando no existía el retablo. Así pues, el aspecto del espacio interno del edificio, cubjerto por armadura mudéjar, con el rutilante reflejo de los azulejos y el cromatismo de las pinturas murales del

13. F. COLLANTES DE TERÁN, op. cit., pp. 23-24; J. GESTOSO, op. cit., III, pp. 523-524. 
presbiterio fue muy diferente al actual, pues aun cuando no sepamos cual fuera la apariencia de las naves, hemos de recordar que a los pies de la nave lateral derecha existía una bellísima pila bautismal de cerámica vidriada en verde, de fines del siglo XV o comienzos del XVI, que fue depositada por la Diputación Provincial en el Museo de Bellas Artes y en la actualidad se conserva en el Museo Arqueológico de Sevilla ${ }^{14}$.

Al exterior destaca el desarrollo macrocefálico del ábside sobre cuyo lado derecho se eleva el octógono del campanario. Este debió ser al principio una sencilla espadaña situada en la parte superior de la terraza que pisa la bóveda del presbiterio, siendo sustituida posteriormente por una construcción de mayor porte en cuyos ritmos de arcadas y frontones triangulares y curvos alternando respectivamente con huecos ciegos en el cuerpo de campanas, vemos una obra coetánea a la de la fachada serliana de la segunda mitad del siglo XVI.

La prolongada cabecera aparece coronada de almenas escalonadas o de gradas, en relieve, sobre el antepecho, es decir, que no quedan exentas, siguiendo en esto una disposición que se encuentra también en la iglesia de la Cartuja de Sevilla, la parroquia de La Algaba, o la capilla de Maese Rodrigo ${ }^{15}$. Sobre el cuerpo de la iglesia se alza el tejado a dos aguas, quedando entre éste y la portada una crujía de fachada correspondiente a una ampliación posterior del Hospital, que llega casi a la altura del óculo del piñón de la iglesia. Por consiguiente, la portada de la iglesia debió ser desmontada en la segunda mitad del siglo XVIII y trasladada a la nueva fachada, como evidencian tanto los caracteres estilísticos de la misma como el azulejo con la imagen de San Lázaro colocado sobre ella.

La portada, en ladrillo agramilado, consiste en un arco de medio punto enmarcado por un alfiz, cuya disposición y molduras coinciden con las de obras realizadas bajo el reinado de los Reyes Católicos.

Si consideramos que el tipo de cabecera es semejante a la de la capilla de Maese Rodrigo, que fue consagrada en 1506 y cuya portada fue contratada en $1514^{16}$, y además tenemos presente que la pila bautismal antes mencionada no debe datarse más allá de esas fechas, podemos concluir que la iglesia del Hospital de San Lázaro debió construirse entre fines del siglo XV y comienzos del siglo XVI.

14. Museo Provincial de Bellas Artes de Sevilla. Madrid, 1967, n. ${ }^{\circ} 34$, p. 52; Catálogo del Museo Arqueológico de Sevilla. II, 3. ㄹ. ed., 1980, n.ำ 9, p. 199; J. M. SERRERA: Pedro de Villegas Marmolejo. Sevilla, 1976, p. 68.

15. D. ANGULO: Arquitectura mudéjar sevillana de los siglos XIII, XIV y XV. Sevilla, 1932, p. 62. Sobre el azulejo de la portada vid A. PLEGUEZUELO, "Azulejos hagiográficos sevillanos del siglo XVIII", Archivo Hispalense, 1979, pp. 167-186.

16. D. ANGULO, op. cit., p. 137. Con posterioridad no se han hecho mayores precisiones respecto a la cronología de la iglesia del Hospital de San Lázaro, Cf. A. MORALES et alii: Guía artística de Sevilla y su provincia. Sevilla, 1981, p. 214. 
No conocemos ningún otro lazareto u hospital para leprosos en España con el que podamos establecer relaciones de analogía a la hora de analizar el edificio que nos ocupa. Ahora bien, de los tres tipos de hospitales frecuentes en nuestra arquitectura, es decir, basilicales, cruciformes y palacianos ${ }^{17}$, podríamos clasificarlo dentro del grupo de estos últimos.

El hospital de tipo palaciano, entre los que se encuentra el Hospital de Santa María de Lérida, el de Medina del Campo y el de Santiago de Ubeda, se caracteriza por ser un conjunto cuadrado o rectangular en torno a un patio, al fondo del cual o a un lado se halla la iglesia ${ }^{18}$.

En este tipo palaciano en que se unifican y conviven las formas góticas y renacentistas, se desligan las funciones religiosas de las hospitalarias propiamente dichas que en la Edad Media tenían lugar en el mismo espacio basilical con camas a ambos lados y altar en la cabecera, como ocurrió en el Hospital del Rey en Burgos. Ahora, las enfermerías se sitúan en las crujías que conforman el patio mientras que la actividad cultual y piadosa se recluye en la iglesia.

Si prescindimos de la crujía de fachada levantada en el siglo XVIII y que se antepone al hastial de la iglesia, enlazando con la portada principal de ingreso al edificio, vemos como la segunda crujía, paralela a la primera, unía los pies de la iglesia con el macizo de muros de la torre de los Gausines, enmascarada en el acceso al Hospital.

Habida cuenta de las múltiples y modernas transformaciones del edificio, parece posible que otras dos crujías, una de ellas al fondo del patio, frente a la puerta de entrada, y otra paralela a la planta de la iglesia, hayan conformado el núcleo del primitivo edificio, de planta trapezoidal, con un patio al que abrían las salas, situándose la iglesia al lado meridional. Este esquema sería semejante al del Hospital de Santa María de Lérida, o al del Hospital de Medina del Campo, antes mencionados.

Dado el plan de reorganización de hospitales emprendido por los Reyes Católicos, no resulta difícil pensar que a su reinado se deba la obra de la iglesia si consideramos además sus características antes enunciadas y los privilegios concedidos al Hospital.

Por entonces, existía inmediata a la fachada una galería cubierta que servía de lugar de descanso para los viajeros como prueba el hecho de que en 1508, la

\footnotetext{
17. V. LAMPÉREZ, op. cit., II, pp. 251-255. Vid una nueva clasificación en R. DÍEZ DEL CORRAL, y F. CHECA, "Typologie hospitalière et bienfaisance dans l'Espagne de la Renaissance: Croix grecque, panthéon, chambres des merveilles", Gazette de Beaux Arts, CVII, 1986, pp. 119-126. Cf. también A. MORALES ET ALII, Arquitectura del Renacimiento en España (1488-1599) Madrid, 1989, pp. 229-230.

18. V. LAMPÉREZ, ibídem, p. 283.
} 
reina Doña Juana dispusiera que la ciudad de Sevilla pagase anualmente mil maravedíes para su reparación por ser de servicio público ${ }^{19}$.

A las obras emprendidas a fines del siglo XV continuaron otras en la segunda mitad del siglo XVI, que le dieron al Hospital su conformación moderna. Estas consistieron en una nueva fachada que arrancando del núcleo de la torre, en cuya base se abrió la portada principal, se prolongó paralelamente unos cincuenta metros sobrepasando el costado septentrional del núcleo del primitivo edificio.

Esta fachada posee un carácter plenamente manierista, e inspirándose en modelos del libro IV de Serlio, constituye un espléndido homenaje hispalense al famoso arquitecto boloñés.

Compuesta de dos cuerpos, se articula en función de tres módulos diferentes que se repiten hasta ocho veces. El correspondiente a la planta baja sigue el modelo de la puerta representada en el folio IX del libro IV, mientras que en el cuerpo superior se combinan dos diferentes: el vano se inspira en el folio XLIIII del mismo libro y la compartimentación del macizo probablemente en el vano central de una casa veneciana del folio XXXV, aun cuando aquí se introduce un óculo en la parte superior que no existe en aquel modelo ${ }^{20}$. La puerta de entrada, con frontón curvo y roto, sobre un hueco adintelado que flanquean dos columnas fajadas en las que se sitúa un entablamento liso, quedando la composición coronada por el balcón, deriva asimismo del folio XXVIII del citado tratado.

$\mathrm{El}$ primer cuerpo se estructura por semicolumnas de orden toscano que alternan con arcos de medio punto, todo ello construido en ladrillos que simulan sillares, al tiempo que corre a lo largo de la fachada un friso de triglifos y metopas que antes estuvieron constituidas por platos de cerámica. En el cuerpo superior, el vano cabalga sobre el macizo inferior, quedando flanqueado por columnas de orden jónico sobre las que reposa entablamento liso y frontón recto.

Comoquiera que la versión castellana del IV Libro de Sebastián Serlio data de 1552 , tenemos pues una fecha "post-quem" para situar cronológicamente la fachada del Hospital de San Lázaro. Por otra parte, si consideramos que Hernán Ruiz II hizo la traza de un crucero cuyo Crucificado y Dolorosa tallaría Juan Bautista Vázquez en 1564, destinado a las inmediaciones del Hospital ${ }^{21}$, parece posible que el Maestro Mayor de la Ciudad de Sevilla haya recibido el encargo de trazar la fachada del Hospital Real de San Lázaro. La alternancia de los

19. F. COLLANTES DE TERÁN, op. cit., p. 23.

20. A. MORALES: "Modelos de Serlio en el arte sevillano", Archivo Hispalense, n. ${ }^{2}$ 200, 1982, p. 154. Cf. SERLIO, Tercero y Quarto Libro de Architectura, Toledo, 1552, ff. IX, XLIIII y XXXV.

21. C. LÓPEZ MARTÍNEZ: El arquitecto Hernán Ruiz en Sevilla. Sevilla, 1949, p. 24. Dicho crucero se encuentra hoy día en la placita de Santa Marta, $C f$. J. HERNÁNDEZ DÍAZ: Imaginería hispalense del Bajo Renacimiento. Sevilla, 1951, p. 31. Sobre la actividad de Hernán Ruiz II como maestro mayor de la ciudad de Sevilla, Vid A. DE LA BANDA: El arquitecto andaluz Hernán Ruiz II. Sevilla, 1974, p. 48, y A. MORALES: $L a$ obra renacentista del Ayuntamiento de Sevilla. Sevilla, 1981, p. 43. 
módulos clasicistas del cuerpo superior con el característico óculo serliano así como el tratamiento en ladrillo del primer cuerpo abonarían nuestra hipótesis.

Resulta difícil poder precisar cómo sería el Hospital en su conjunto a fines del siglo XVI, después de las completas transformaciones y eliminación total de la parte antigua del edificio, exceptuando la crujía de fachada. Sin embargo, parece posible que tras la nueva crujía de fachada haya existido otro patio paralelo al primero que lindaba con la iglesia. De cualquier manera que haya sido, y teniendo en cuenta la provisionalidad de nuestros asertos, que se fundamentan únicamente en el análisis de las formas arquitectónicas del edificio, podemos concluir que en su construcción existieron dos fases: una primera, de fines del siglo XV a comienzos del XVI; otra segunda, en la segunda mitad del siglo XVI, posiblemente hacia 1564 .

\section{V}

Las novedades y mejoras del moderno hospital renacentista tuvieron su traducción nutricional en las disposiciones ordenadas por Felipe II en 1573, por las que se observaba todo lo establecido por los Reyes Católicos, y además se incrementaba la ración alimenticia de los pobres enfermos ${ }^{22}$. Sin embargo, esta situación de bonanza no llegaría más allá de mediados del siglo XVII, siendo también un reflejo de las crisis sociales y económicas de aquel siglo. Así, por ejemplo, en 1652, el Hospital estaba endeudado por las obras que hubieron de realizarse para alojar a los convalecientes de la epidemia de 1649, época luctuosa que supuso la despoblación de la ciudad y la creación de nuevos cementerios, uno de ellos frente a San Lázaro en la confluencia de la antigua calzada con el camino al actual del siglo XIX ${ }^{23}$.

No conocemos cuál haya sido el alcance de aquellas obras, pero no debieron ser mayores que las realizadas en el siglo XVIII, cuando el Hospital luchando por su subsistencia sostiene un pleito contra la Casa de Alba por el tributo de seis docenas de atunes de las almadrabas de Conil y Vejer, que aunque fue ganado nunca llegó a ser cobrado ${ }^{24}$.

Estas obras debieron terminarse en 1761, cuando era Mayoral Diego de Torres Margan, caballero veinticuatro de Sevilla, como reza el azulejo del escudo real que está sobre el balcón de la puerta principal, azulejo de idéntico estilo que el que aparece sobre la portada de la iglesia. En efecto, es la crujía que arranca desde la portada de la iglesia, prolongando la línea de fachada levantada en el siglo XVI, la que se terminó en aquella fecha como evidencia no sólo la forma de las ventanas, sino el estilo y la data de los azulejos.

22. F. COLLANTES DE TERÁN, op. cit., p. 35.

23. F. COLLANTES DE TERÁN, ibídem. p. 37

24. A. HERMOSILLA: "Los Hospitales Reales" en Los Hospitales de Sevilla. Sevilla, 1989, p. 45. 
Después de las demoliciones y transformaciones realizadas en los siglos XIX y XX, difícilmente podremos obtener una idea de la planta general del edificio a menos que apareciera alguna vez un plano antiguo del mismo. No obstante, la lectura del Inventario de bienes del Hospital de San Lázaro, realizada en 1812, puede iluminarnos acerca de su estructura y distribución en los días del Antiguo Régimen, pues allí se mencionan después de la iglesia y su sacristía: Cuarto del cementerio, cuarto del cura, clavería, archivo, enfermería alta para hombres, enfermería alta de mujeres, granero alto, crujía de la calle, refectorio, cocina, despensa, almacén del aceite, lavaderos, cuarto de prisiones, guardilla, caballeriza, carbonera y leñería ${ }^{25}$.

La enfermería alta para hombres se describe como "una quadra larga con seis ventanas dos con puertas: dos con rejas y puerta: y dos más chicas con dos pares de puertas de cristal" ${ }^{26}$; este número de vanos coincide con los de la crujía de fachada entre la iglesia y la portada principal, crujía que debió construirse en el siglo XVIII, como hemos afirmado anteriormente.

La enfermería alta de las mujeres consistía en "una quadra alta para mugeres sin acabar con puerta principal a la de los hombres con serrojo y llave para que puedan oír misa en el oratorio". Es decir, existía clara separación entre un ámbito y otro, comunicándose entre sí únicamente con ocasión de la misa o en caso de necesidad. Ambas enfermerías altas tuvieron acceso por distintas escaleras y la sala de mujeres pudo ser paralela a la de hombres, manteniéndose en el uso del oratorio la pervivencia medieval de la capilla en la nave del hospital para atención espiritual de los enfermos incurables.

En la crujía de la calle se menciona "la casa alta del Sr. Mayoral" y a continuación el refectorio, sin mayor descripción ${ }^{27}$. Si seguimos atentamente la lectura del texto vemos que el Inventario se realizó partiendo de la iglesia en dirección Norte. Así pues, la vivienda del Mayoral, siguiendo este orden, se situaba en la planta alta de la crujía correspondiente a la fachada serliana del siglo XVI mientras que el refectorio se situaría probablemente en la planta baja de la misma, ya que a renglón seguido se mencionan la cocina, despensa y almacén de aceite.

El aspecto general del Hospital de San Lázaro en el siglo pasado no debió ser muy diferente al que se trasluce de la citada relación de 1812. Ahora bien, las

25. Inventario de los muebles, alajas y efectos del Real Hospital de San Lázaro. Extramuros de la Ciudad de Sevilla (1812), (Leg. 25, 2.4, s.p., Archivo Diputación Provincial de Sevilla).

26. Ihidem.

27. Ibidem. 
condiciones de mantenimiento no fueron a mejor sino todo lo contrario, pues en 1831, el famoso viajero inglés Richard Ford dice claramente que "el interior es de pena", utilizándose los fondos para propio uso de los administradores, pero no en beneficio de la institución ${ }^{28}$.

Con posterioridad a 1840, la parte del edificio destinada a la administración amenazaba ruina y llegó a hipotecarse la llamada Huerta Grande de San Lázaro con objeto de obtener un préstamo ${ }^{29}$. Exonerado del patronato real en 1854 , a consecuencia de la ley de Beneficencia, el edificio se encontraba en completa ruina, sobre todo el ala Norte, es decir, la correspondiente a la fachada del siglo XVI, encontrándose los enfermos en habitaciones bajas de los patios interiores ${ }^{30}$.

Las malas condiciones del edificio y el desorden de la institución tuvieron un punto final cuando en 1864, bajo la dirección del Sr. José María Ibarra, se invirtieron 142.662 reales en unas obras generales de reparación que reformaron sustancialmente el edificio "dándole distribución conveniente para comodidad de los enfermos" "31, como manifiesta la lápida conmemorativa.

Con motivo de esta reforma de 1864, se encargaron del cuidado de los enfermos, estableciéndose en esta institución, las hermanas de la Caridad, que han continuado hasta la fecha.

Las obras emprendidas por José María de Ibarra, primer Conde de Ibarra, persistieron bajo su munificencia aún después de su muerte, siendo costeadas por sus hijos según disposición testamentaria, como recuerda una inscripción de 1878 , en la que se nos informa que se construyeron galerías, salas de descanso, refectorio de mujeres y otras oficinas ${ }^{32}$.

Después de terminadas las obras, se colocó una verja de hierro en el jardín separando el espacio que precede a la fachada del edificio del camino que conducía al cementerio de San Fernando. Esta verja fue costeada por los Diputados Provinciales Fernando de Silva y Manuel Vázquez Rodríguez, quienes cedieron graciosamente sus sueldos como miembros de la Comisión permanente ${ }^{33}$. La verja duró allí hasta nuestros días, cuando desapareció el jardín anterior y se transformó totalmente el entorno de la antigua huerta de San Lázaro.

\footnotetext{
28. R. FORD: Manual para viajeros por Andalucía. Madrid, 1980, p. 262: "El interior es de pena, ya que los fondos de este verdadero lazareto son utilizados por los administradores para su uso personal más que otra cosa. Aquí se pueden ver casos de elefantiasis, la horrible pierna hinchada, una enfermedad corriente en Berbería, y no rara en Andalucía, que propaga el mismo paciente, que mendiga la caridad entre los viajeros, cuyos ojos se sienten sobresaltados y doloridos por lo que al principio parece una inmensa y cancerosa boa constrictor".

29. F. COLLANTES DE TERÁN, op. cit., p. 25.

30. F. COLLANTES DE TERÁN, ibídem, p. 26.

31. Ibidem, p. 27.

32. Ibídem.

33. Ibidem, nota 1.
} 


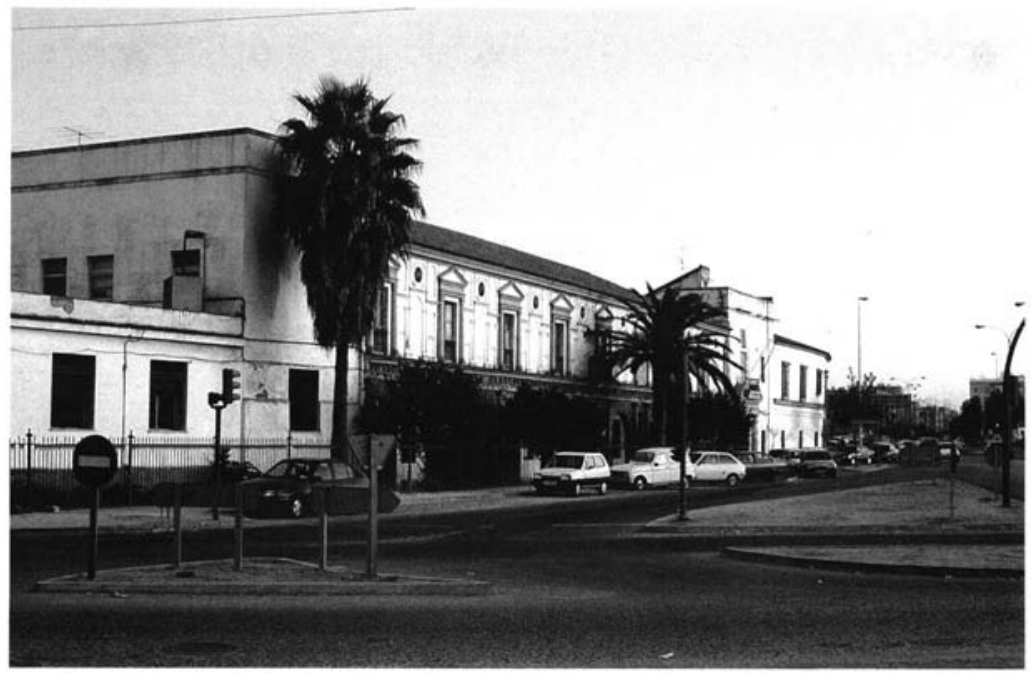

Lámina 1 


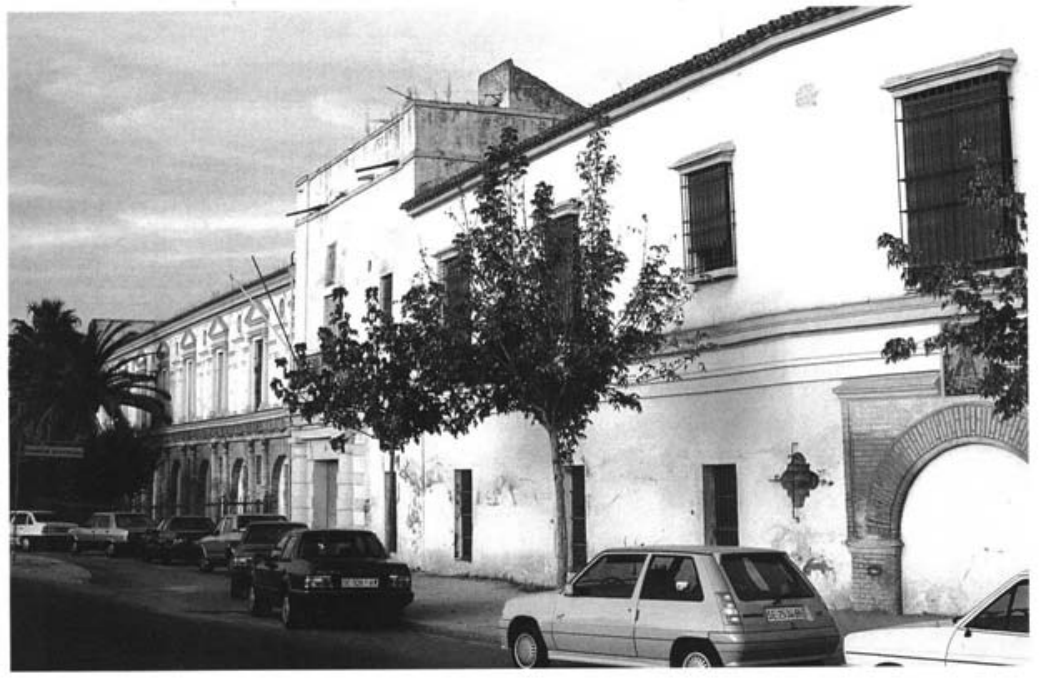

L.amina 2

Fachada principal del Hoxpital de San Lizaro (R. Cómez) 


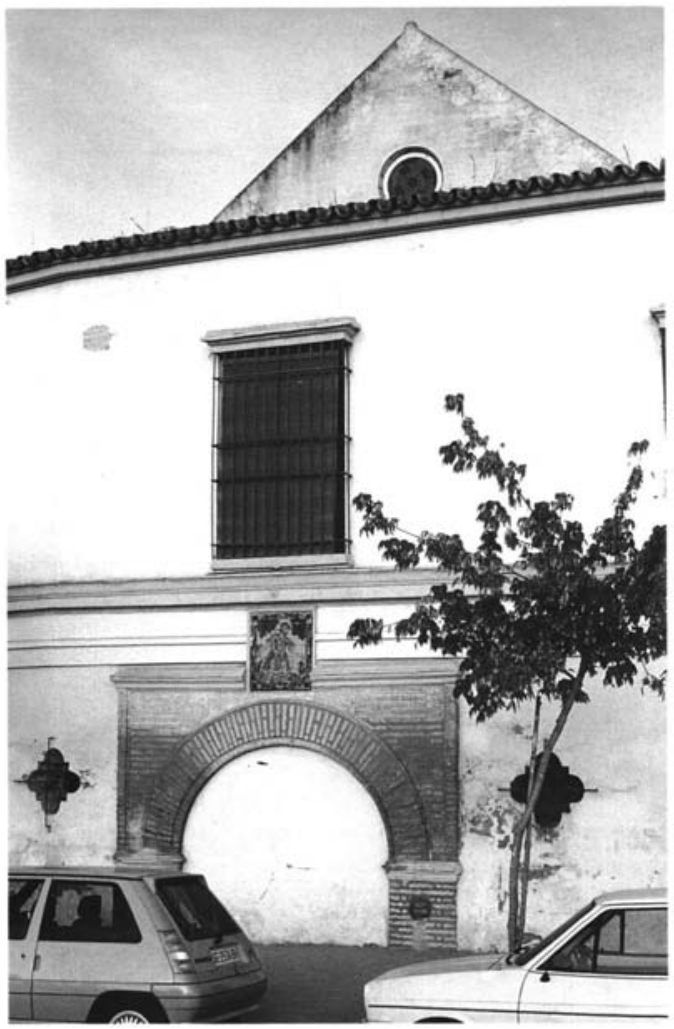

Lámina 3

Portada de la iglesia del Hospital de San Lázaro (R. Cómez) 


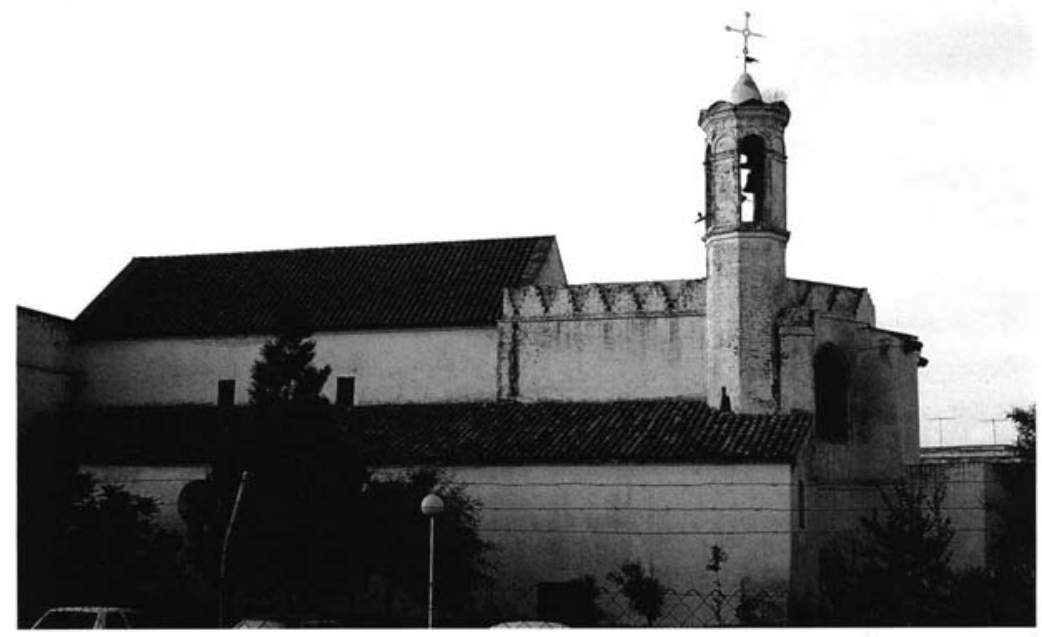

Lámina 4

Iglesia del Hospital de San Lázaro (R. Cómez) 


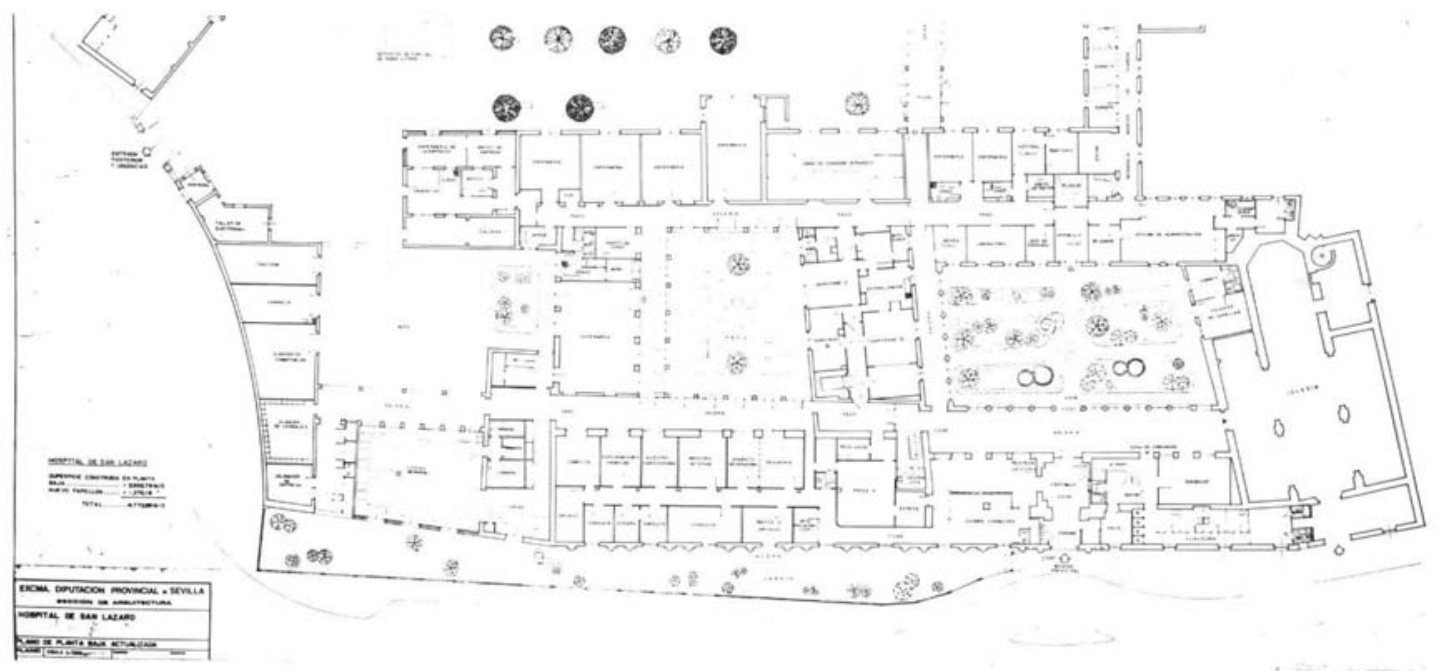

I.ámina 5

Planta actual del Hospital de San Lázaro 